\title{
Recombinant Rat CC10 Protein Inhibits PDGF-Induced Airway Smooth Muscle Cells Proliferation and Migration
}

\author{
Ying Wei, Yu-Dong Xu, Lei-Miao Yin, Yu Wang, Jun Ran, Qi Liu, Zi-Feng Ma, \\ Yan-Yan Liu, and Yong-Qing Yang
}

Laboratory of Molecular Biology, Yueyang Hospital of Integrated Traditional Chinese and Western Medicine, Shanghai University of Traditional Chinese Medicine, 650 South Wanping Road, Shanghai 200030, China

Correspondence should be addressed to Yong-Qing Yang; yyq@shutcm.edu.cn

Received 8 April 2013; Revised 24 June 2013; Accepted 11 August 2013

Academic Editor: Elena Orlova

Copyright (c) 2013 Ying Wei et al. This is an open access article distributed under the Creative Commons Attribution License, which permits unrestricted use, distribution, and reproduction in any medium, provided the original work is properly cited.

\begin{abstract}
Abnormal migration and proliferation of airway smooth muscle cells (ASMCs) in the airway cause airway wall thickening, which is strongly related with the development of airway remodeling in asthma. Clara cell $10 \mathrm{kDa}$ protein (CC10), which is secreted by the epithelial clara cells of the pulmonary airways, plays an important role in the regulation of immunological and inflammatory processes. Previous studies suggested that CC10 protein had great protective effects against inflammation in asthma. However, the effects of CC10 protein on ASMCs migration and proliferation in airway remodeling were poorly understood. In this study, we constructed the pET-22b-CC10 recombinant plasmid, induced expression and purified the recombinant rat CC10 protein from $E$. coli by $\mathrm{Ni}^{2+}$ affinity chromatography and ion exchange chromatography purification. We investigated the effect of recombinant rat CC10 protein on platelet-derived growth factor (PDGF)-BB-induced ASMCs proliferation and migration. Our results demonstrated that the recombinant CC10 protein could inhibit PDGF-BB-induced cell viability, proliferation and migration. Western blot analysis showed that PDGF-BB-induced activation of cyclin D1 was inhibited by CC10. These findings implicated that CC10 could inhibit increased ASMCs proliferation, and migration induced by PDGF-BB, and this suppression effect might be associated with inhibition of cyclin D1 expression, which might offer hope for the future treatment of airway remodeling.
\end{abstract}

\section{Introduction}

Asthma is a chronic airway inflammatory disease which has the characteristics of airway hyperresponsiveness, airway inflammation, and airway remodeling. Persistent inflammation in airway may lead to structural changes known as airway remodeling [1]. More and more evidence indicated that airway remodeling is closely related to the progression of airway hyperresponsiveness and the severity of asthma. One of the dominant structural changes of airway remodeling is the increase in airway smooth muscle (ASM) mass [2]. It was demonstrated that a histological thickness of smooth muscle was increased in asthmatic airways [3]. Increased ASMCs proliferation and migration is responsible for this ASM thickness change and contributes to the remodeling of the smooth muscle within the airway wall [4]. Increased proliferation and migration decreased pulmonary function in asthmatic patients [4-6]. Considering that airway remodeling in asthma is poorly responsive to current therapies [2], it will be valuable to search for new molecules to prevent airway remodeling.

It appeared that PDGF had a prominent role in promoting smooth muscle proliferation and migration. The PDGF family is composed of five different dimeric isoforms: PDGF-AA, PDGF-AB, PDGF-BB, PDGF-CC, and PDGF-DD [7]. PDGF, which was secreted by epithelial cells and inflammatory cells from asthmatic airways [8-10], had been shown to be elevated in the lungs of asthmatics and was thought to contribute to airway remodeling and ASM proliferation [11, 12].

Clara cell $10 \mathrm{kDa}$ protein $(\mathrm{CC} 10)$, which is produced by the nonciliated, nonmucous, secretory epithelial clara cells of the pulmonary airways, was first identified in lung lavage by Singh and colleagues [13-15]. CC10 consists of a homodimer of 70-77 amino acid polypeptides held together by two disulfide bridges arranged in antiparallel fashion [16]. Previous studies has suggested that $\mathrm{CC} 10$ have great protective effects against inflammation in asthma [17-21]. However, the effects of CC10 protein on airway remodeling were poorly 
understood. In this study, we constructed the pET-22b-CC10 recombinant plasmid, induced expression, and purified the recombinant rat CC10 protein from $E$. coli by $\mathrm{Ni}^{2+}$ affinity chromatography and ion exchange chromatography purification. We investigated the effect of recombinant rat CC10 protein on PDGF-BB-induced ASMCs proliferation and migration. We showed here that recombinant rat CC10 protein had inhibitory effect on PDGF-BB-induced ASMCs proliferation and migration in airway remodeling.

\section{Materials and Methods}

2.1. Reagents. E. coli strain BL21 (DE3) was a generous gift from Shanghai National Engineering Center for Biochips. pET-22b plasmid was a gift from the Pharmaceutical Institute of Chinese Academy of Sciences. WST-1 Cell Proliferation and Cytotoxicity Assay Kit and the fluorescent dye DAPI were purchased from Beyotime. $\mathrm{Ni}^{2+}$ Sepharose 6 Fast Flow and Q Sepharose Fast Flow were purchased from GE Healthcare. PDGF-BB was purchased from R\&D Systems. Dulbecco's modified Eagle's medium (DMEM), PBS, and penicillin streptomycin solution were purchased from Hyclone. Fetal bovine serum (FBS) and $0.25 \%$ Trypsin-EDTA solution were purchased from Gibco. 96-well plates, 6-well plates, and Boyden chamber were purchased from Corning Costar. E-Plate 16 was purchased from Roche. Antibody against cyclin D1 was purchased from Epitomic. Antibody against $\alpha$-smooth muscle actin and TRITC-conjugated goat anti-rabbit IgG were purchased from Abcam.

2.2. Recombinant Plasmid Construction. Rat CC10 coding region sequences were obtained from Gene Bank, NM_013051.1 and were amplified by PCR. The $5^{\prime}$ primer used was $5^{\prime}$-GGAATTCCATATGAAGATCGCCATCACAATCA$3^{\prime}$ and the $3^{\prime}$ primer used was $5^{\prime}$-CCGCTCGAGGACTCTTAAATCTTGCTCACAC- $3^{\prime}$. The recombinant pET-22bCC10 plasmids containing the synthetic CC10 gene were cloned through Nde I and Xho I restriction sites and were transformed into host cell BL21 (DE3). The positive colonies containing the recombinant pET-22b-CC10 plasmids were screened by colony PCR and sequencing analysis.

\subsection{Expression and Purification of the Recombinant Rat CC10} Protein. For recombinant protein expression, positive E. coli strain containing recombinant $\mathrm{pET}-22 \mathrm{~b}-\mathrm{CC} 10$ plasmid was induced by addition of isopropyl- $\beta$-D-thiogalactopyranoside (IPTG). After IPTG induction, the bacterial pellets were collected by centrifugation. The bacterial pellets were resuspended in buffer A (20 mM sodium phosphate, $500 \mathrm{mM}$ $\mathrm{NaCl}, 20 \mathrm{mM}$ imidazole, $\mathrm{pH}$ 8.0) and lysed by lysozyme. The lysate was centrifuged, and the supernatant was collected. The recombinant rat CC10 protein in the supernatant was purified by affinity chromatography purification using $\mathrm{Ni}^{2+}$ Sepharose 6 Fast Flow beads and ion exchange chromatography purification using Q Sepharose Fast Flow beads by gravity flow according to the manufacturer's instructions. SDS-PAGE gels and Western blotting were used for purity analysis and antigenic activity assay.
2.4. Isolation, Characterization, and Culture of Rat ASMCs. ASMCs were isolated from the airway of SD rat conforming to the regulations of the State Science and Technology Commission. The rat tracheal was dissected under sterile conditions in normal saline solution. The smooth muscle layer was dissected free of the adherent connective tissue and cartilage, and the epithelial layer was removed. The smooth muscle section was then chopped finely into $1 \mathrm{~mm} \times 1 \mathrm{~mm}$ tissues and incubated in $12 \mathrm{~cm}^{2}$ flasks for $3 \mathrm{~h}$ in $3 \mathrm{~mL}$ DMEM supplemented with $10 \%$ FBS, $100 \mathrm{U} / \mathrm{mL}$ penicillin, and $0.1 \mathrm{mg} / \mathrm{mL}$ streptomycin at $37^{\circ} \mathrm{C}$ in humidified air containing $5 \% \mathrm{CO}_{2}$. Then, the smooth muscle tissues were cultured in $5 \mathrm{~mL} 10 \%$ FBS-DMEM for 5 days and changed with fresh culture medium every three days. ASMCs were grown until they formed a confluence and passaged with $0.25 \%$ trypsin-EDTA solution. The characteristic of ASMCs were determined by immunofluorescence with antibodies against $\alpha$-smooth muscle actin. All experiments were performed with ASMCs from passages 6 to 12 .

2.5. Cell Proliferation/Viability Assay. To estimate cell proliferation/viability, we performed WST-1 assay and Roche Real-Time Cell Analyzer (RTCA) DP assay. WST-1 cell proliferation assay which was designed to measure the relative proliferation rates of cells in culture is commonly used for the nonradioactive quantification of cellular proliferation. WST-1 reagent is a colorimetric assay, and it is an alternative product for MTT and XTT. The principle of WST-1 assay is that it could be converted into a colored dye by mitochondrial dehydrogenase enzymes which are proportional to the cell number. Compared with the traditional label-based endpoint assays like WST-1, the Roche RTCA assay has emerged as an alternative noninvasive and label-free approach to assess cellular proliferation, migration, and invasion in realtime on a cell culture level with specific plates designed for different research purposes $[22,23]$. The RTCA assay measures impedance changes in a meshwork of interdigitated gold microelectrodes located at the well bottom of E-plate 16. These changes are caused by the gradual increase of electrode surface occupation by proliferated cells during the course of time, and thus, can provide an index of cell viability and proliferation [24].

ASMCs were seeded into 96 well plate or E-Plate 16 at a density of 3000 cells/well with DMEM containing 10\% FBS. The cells were growth arrested by withdrawing serum for $24 \mathrm{~h}$. Then, cells were treated with increasing doses of CC10 protein $(1 \mathrm{ng} / \mathrm{mL}, 10 \mathrm{ng} / \mathrm{mL}, 50 \mathrm{ng} / \mathrm{mL}, 100 \mathrm{ng} / \mathrm{mL}, 200 \mathrm{ng} /$ $\mathrm{mL}, 400 \mathrm{ng} / \mathrm{mL}$, and $800 \mathrm{ng} / \mathrm{mL}$ ) $1 \mathrm{~h}$ before stimulation with PDGF-BB (25 ng/mL) in 1\% FBS-DMEM for $24 \mathrm{~h}$. To compare the effect of CC10 protein on PDGF-BB-induced ASMCs proliferation/viability with hydrocortisone (HC, a widely used drug in treating asthma), we performed WST-1 assay and the Roche RTCA DP assay. ASMCs were treated with CC10 protein $(400 \mathrm{ng} / \mathrm{mL})$ or $\mathrm{HC}(1 \mathrm{mg} / \mathrm{mL}) 1 \mathrm{~h}$ before stimulation with PDGF-BB (25 ng/mL) in 1\% FBS-DMEM for $24 \mathrm{~h}$, $48 \mathrm{~h}$, and $72 \mathrm{~h}$. The cell proliferation/viability was determined using the Roche RTCA DP assay/WST-1 assay according to the manufacturer's instructions. Data were generated from ASMCs with 4 replicates. 


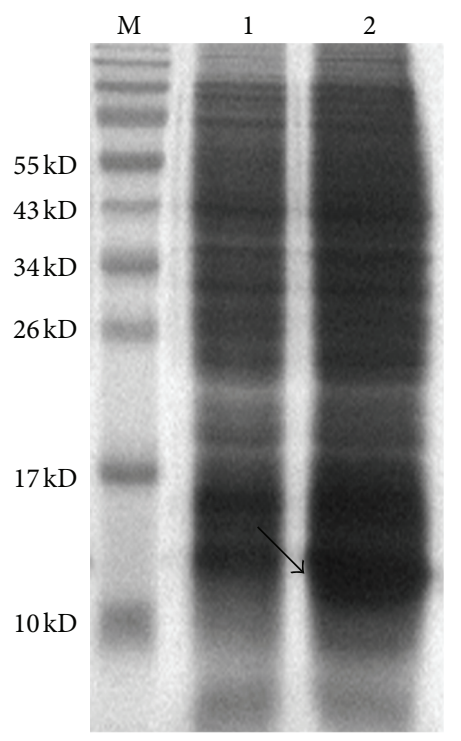

(a)

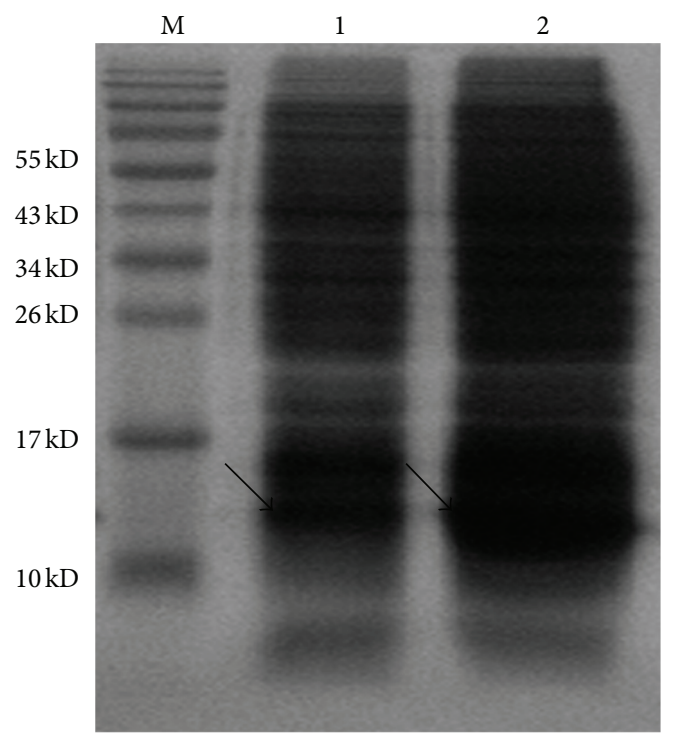

(b)

FIGURE 1: Induced expression and soluble analysis of recombinant rat CC10 protein. (a) Induced expression of recombinant CC10 protein; 1: uninduced recombinant pET-22b-CC10 culture; 2: induced recombinant pET-22b-CC10 culture. (b) Soluble analysis of the induced expression of recombinant CC10 protein; 1 : insoluble pellet of the induced recombinant pET-22b-CC10 culture; 2: clarified supernatant of the induced recombinant pET-22b-CC10 culture.

2.6. Boyden Chamber Migration Assay. The migration assay was performed using the Transwell system. The lower compartment was filled with $0.6 \mathrm{~mL}$ of DMEM containing $1 \%$ FBS with $25 \mathrm{ng} / \mathrm{mL}$ PDGF-BB alone or together with CC10 $(400 \mathrm{ng} / \mathrm{mL})$ or HC $(1 \mathrm{mg} / \mathrm{mL})$. ASMCs $\left(1 \times 10^{5}\right)$ were resuspended in $0.1 \mathrm{~mL}$ of DMEM and placed in the upper part of the Transwell plate. Cells were incubated for $8 \mathrm{~h}$ in a humidified atmosphere of $5 \% \mathrm{CO}_{2}$ at $37^{\circ} \mathrm{C}$. ASMCs were fixed with $4 \%$ paraformaldehyde and stained with trypan blue for $10 \mathrm{~min}$. ASMCs on the upper surface of the filter were mechanically removed by wiping with a cotton swab, and the migrated cells were determined by counting the cells that migrated to the lower side of the filter using a microscope. Six randomly selected fields were counted, and each sample was assayed in triplicate.

2.7. Western Blot Analysis. ASMCs were seeded into 6-well plates with 10\% FBS-DMEM. The cells were growth arrested by withdrawing serum for $24 \mathrm{~h}$. Then, cells were treated with CC10 protein $(400 \mathrm{ng} / \mathrm{mL})$ or $\mathrm{HC}(1 \mathrm{mg} / \mathrm{mL}) 1 \mathrm{~h}$ before stimulation with PDGF-BB (25 ng/mL) in 1\% FBS-DMEM for $24 \mathrm{~h}$ and $48 \mathrm{~h}$. The total protein was extracted using RIPA protein extraction reagent. Immunoblotting was performed with cyclin D1 antibody (1:10000 diluted), $\beta$-actin antibody ( $1: 10000$ diluted), and secondary peroxidase-conjugated IgG (1:10000 diluted). The immunoreactivity was detected by chemiluminescence as previously described [25]. The protein bands were quantified using a Bio-Rad Image Lab calibrated densitometer.

2.8. Statistical Analysis. Results are expressed as mean $\pm \mathrm{SD}$ values. Statistical analyses of the data were performed by oneway analysis of variance (ANOVA) for multiple comparisons followed by the LSD test for comparisons between groups. Values of $P<0.05$ were considered statistically significant.

\section{Results}

3.1. Expression and Purification of Recombinant CC10 Protein. The expression of CC10 was induced by IPTG, and the optimal condition at which we arrived was induction of CC10 for $4 \mathrm{~h}$ with $0.4 \mathrm{mM}$ IPTG at $21^{\circ} \mathrm{C}$ (Figure $1(\mathrm{a})$ ). SDS-PAGE analysis of the supernatant and pellet showed that the recombinant CC10 protein was mainly expressed in soluble form (Figure 1(b)). The recombinant rat CC10 protein was purified by affinity chromatography purification using $\mathrm{Ni}^{2+}$ Sepharose 6 Fast Flow beads and ion exchange chromatography purification using Q Sepharose Fast Flow beads. After this two-step purification, we obtained the recombinant rat CC10 protein in high purity with a single visible band (Figure 2). Western blot analysis with antibodies against CC10 demonstrated its antigenic activity.

\subsection{Recombinant Rat CC10 Protein Inhibits PDGF-BB-} Induced ASMCs Viability/Proliferation. We examined the effect of increasing doses of CC10 (1 ng/mL, $10 \mathrm{ng} / \mathrm{mL}, 50 \mathrm{ng} /$ $\mathrm{mL}, 100 \mathrm{ng} / \mathrm{mL}, 200 \mathrm{ng} / \mathrm{mL}, 400 \mathrm{ng} / \mathrm{mL}$, and $800 \mathrm{ng} / \mathrm{mL}$ ) on PDGF-BB-induced ASMCs viability. In the WST-1 assay system, ASMCs showed a 134\% increase in cellular viability compared to the PBS control after stimulation with $25 \mathrm{ng} / \mathrm{mL}$ PDGF-BB for $24 \mathrm{~h}(P<0.01)$. CC10 protein inhibited ASMCs viability between doses of $1 \mathrm{ng} / \mathrm{mL}$ and $800 \mathrm{ng} / \mathrm{mL}$ (Figure 3). $400 \mathrm{ng} / \mathrm{mL}$ CC10 protein had the strongest inhibitory effect on ASMCs viability among the doses, and we chose this dose for the follow-up study. 


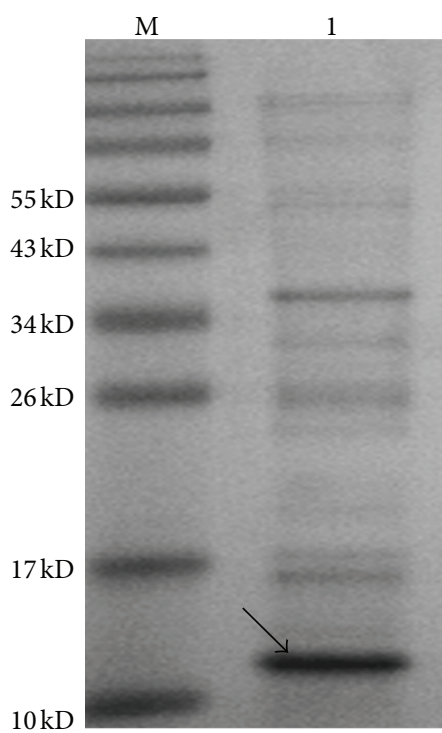

(a)

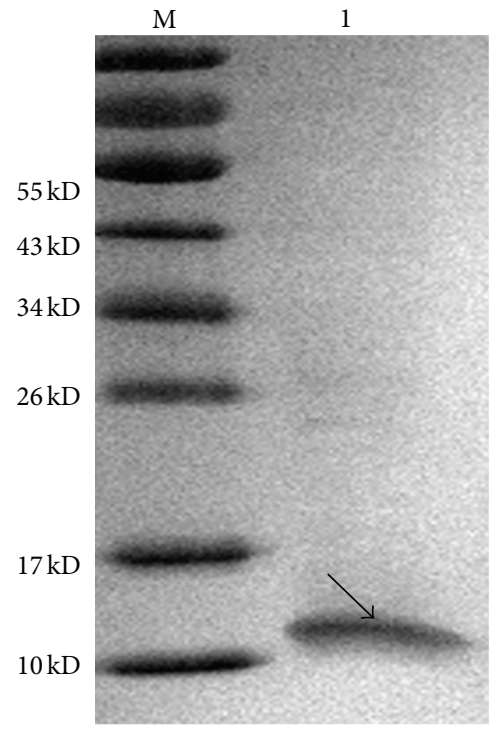

(b)

FIGURE 2: Analysis of the recombinant rat CC10 protein purity by SDS-PAGE; (a) purity of recombinant CC10 protein after affinity chromatography purification; (b) purity of recombinant CC10 protein after affinity chromatography and ion exchange chromatography purification.

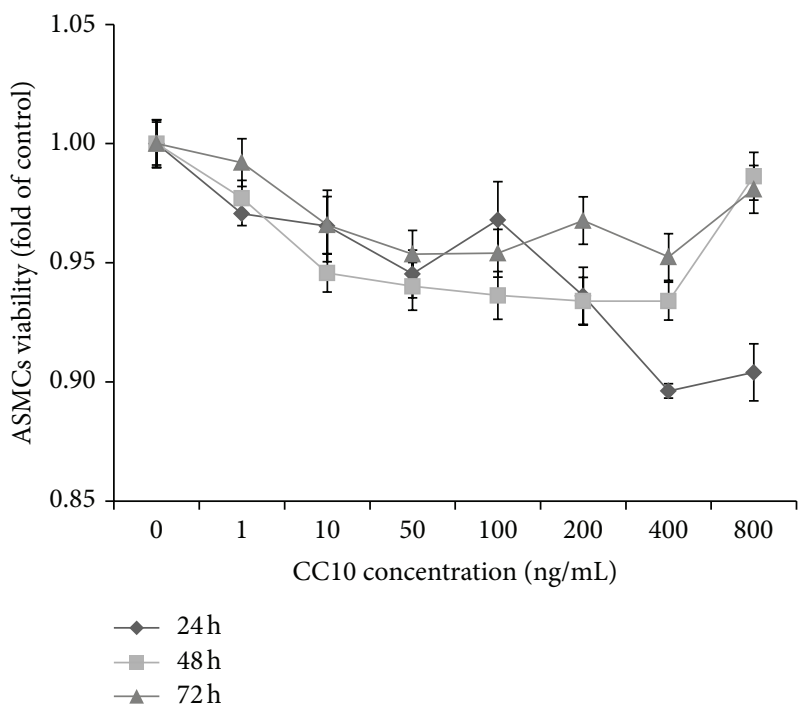

Figure 3: Dose dependent inhibitory effect of CC10 protein on PDGF-BB-induced ASMCs viability. Data was generated from ASMCs with 4 replicates. Percentage of viability was obtained by comparing OD values to that of ASMCs treated in parallel with PDGF-BB.

We compared the effect of $400 \mathrm{ng} / \mathrm{mL}$ CC10 on PDGFBB-induced ASMCs viability and proliferation with HC. In the WST-1 assay system, ASMCs showed 129\%, 134\%, and $124 \%$ increases in cellular viability after stimulation with $25 \mathrm{ng} / \mathrm{mL}$ PDGF-BB for $24 \mathrm{~h}, 48 \mathrm{~h}$, and $72 \mathrm{~h}$ compared to the PBS control $(P<0.01)$. Pretreatment with $400 \mathrm{ng} / \mathrm{mL}$ CC10 suppressed PDGF-BB-induced cellular viability to about
$89 \%, 84 \%$, and $93 \%$ for $24 \mathrm{~h}, 48 \mathrm{~h}$, and $72 \mathrm{~h}$ compared to the PDGF stimulation $(P<0.01)$. Pretreatment with $1 \mathrm{mg} / \mathrm{mL}$ HC suppressed PDGF-BB-induced cellular viability to about $90 \%, 81 \%$, and $76 \%$ for $24 \mathrm{~h}, 48 \mathrm{~h}$, and $72 \mathrm{~h}$ compared to the PDGF group $(P<0.01)$ (Figure $4(\mathrm{a}))$. In the WST-1 assay system, the effect of CC10 protein was the same as that of $\mathrm{HC}$ at $24 \mathrm{~h}(P>0.05)$.

In the Roche RTCA DP assay system, we observed the real-time effect of CC10 protein on PDGF-BB-induced ASMCs proliferation for $72 \mathrm{~h}$. We chose data of $12 \mathrm{~h}, 24 \mathrm{~h}$, $36 \mathrm{~h}, 48 \mathrm{~h}, 60 \mathrm{~h}$, and $72 \mathrm{~h}$ for analysis. Stimulation with PDGFBB $(25 \mathrm{ng} / \mathrm{mL})$ increased ASMCs proliferation to $157 \%(P<$ $0.01)$ for $12 \mathrm{~h}, 160 \%(P<0.01)$ for $24 \mathrm{~h}, 145 \%(P<0.01)$ for $36 \mathrm{~h}, 119 \%(P<0.05)$ for $48 \mathrm{~h}$, and $110 \%$ for $60 \mathrm{~h}$ and $72 \mathrm{~h}$ compared to the PBS control. Pretreatment with CC10 (400 ng/mL) suppressed PDGF-BB-induced cell proliferation to $78 \%$ for $12 \mathrm{~h}, 77 \%$ for $24 \mathrm{~h}, 74 \%$ for $36 \mathrm{~h}, 76 \%$ for $48 \mathrm{~h}, 73 \%$ for $60 \mathrm{~h}$, and $63 \%$ for $72 \mathrm{~h}$ compared to the PDGF group $(P<$ $0.01)$. Pretreatment with $1 \mathrm{mg} / \mathrm{mL}$ HC suppressed PDGF-BBinduced cellular proliferation to about $71 \%$ for $12 \mathrm{~h}(P<0.01)$, $74 \%$ for $24 \mathrm{~h}(P<0.01)$, and $89 \%$ for $36 \mathrm{~h}(P<0.05) \mathrm{com}-$ pared to the PDGF group (Figure 4(b)). In this experimental system, we found out that both $\mathrm{CC10}$ protein and $\mathrm{HC}$ had an inhibitory effect on PDGF-BB-induced ASMCs proliferation. In the first $36 \mathrm{~h}$ after PDGF-BB induction, $\mathrm{CC} 10$ protein and $\mathrm{HC}$ had the same inhibitory effect on cell proliferation $(P>$ $0.05)$. In the time after $48 \mathrm{~h}, \mathrm{HC}$ manifested promotion of ASMCs proliferation, and this promotion of cell proliferation could reach $131 \%$ compared to control $(P<0.01)$. These results demonstrated that CC10 $(400 \mathrm{ng} / \mathrm{mL})$ negatively regulates cellular proliferation in response to PDGF signaling, and this inhibitory effect was stronger than HC after $36 \mathrm{~h}$. 


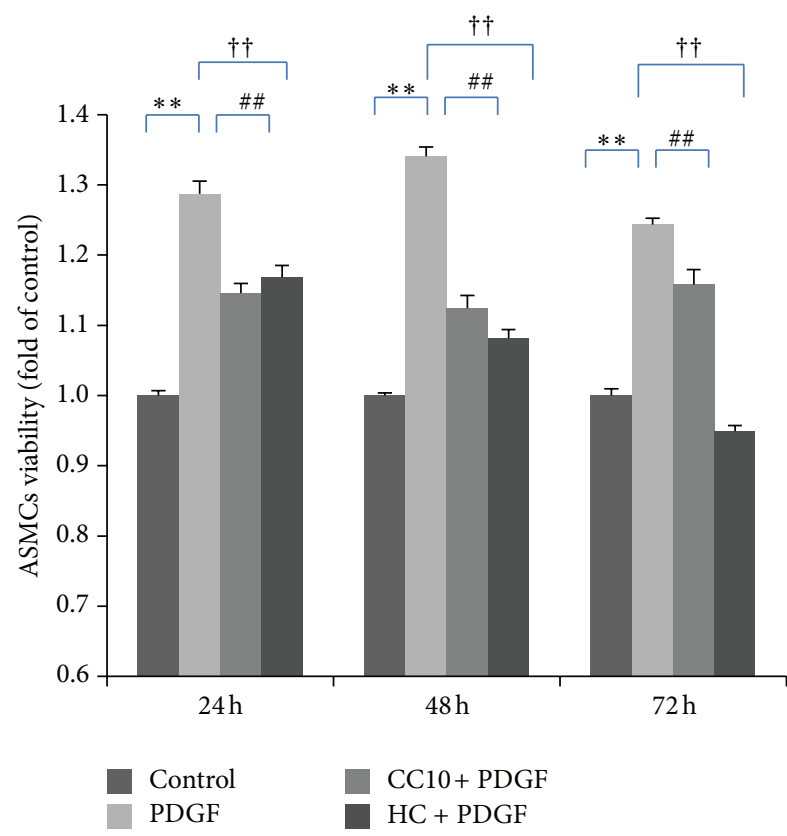

(a)

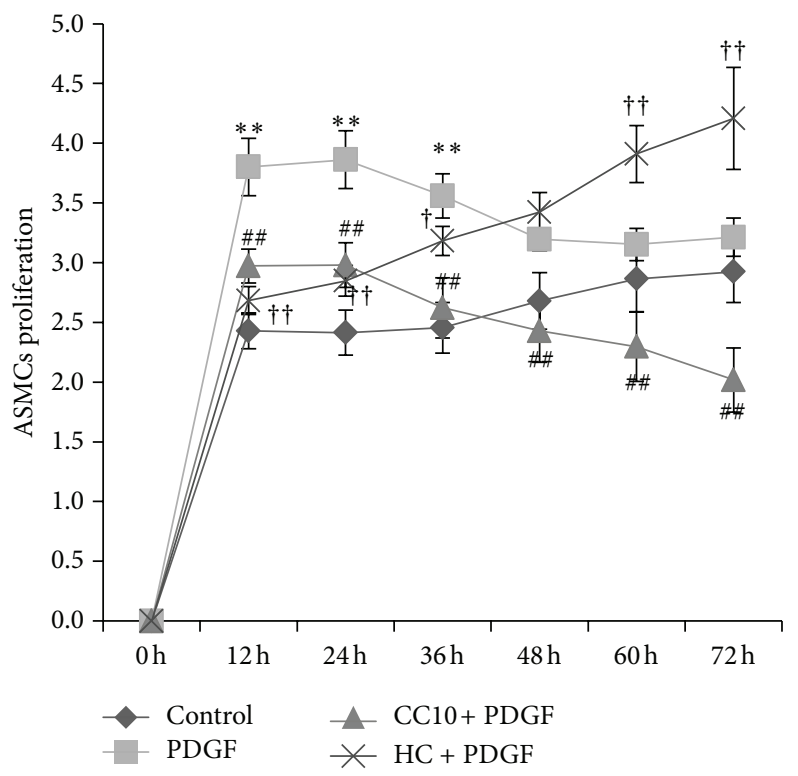

(b)

FIGURE 4: Effects of recombinant rat CC10 protein on PDGF-BB-induced ASMCs viability/proliferation. (a) Comparison of the effect of CC10 protein on ASMCs viability to that of HC by WST-1 assay. (b) Comparison of the effect of CC10 protein on ASMCs proliferation with that of HC by Roche RTCA DP assay. Data was generated from ASMCs with 4 replicates. Percentage of viability was obtained by comparing OD values to that of ASMCs in a control group treated in parallel with PBS. ASMCs proliferation variation was obtained by calculating the changes of ASMCs to baseline. Data was shown as means \pm SD values. ${ }^{* *} P<0.01$ PDGF group versus control, ${ }^{*} P<0.05$ PDGF group versus control, ${ }^{\# \#} P<0.01 \mathrm{CC} 10$ group versus PDGF group, ${ }^{\dagger \dagger} \mathrm{P}<0.01 \mathrm{HC}$ group versus PDGF group, and ${ }^{\dagger} P<0.05 \mathrm{HC}$ group versus PDGF group.

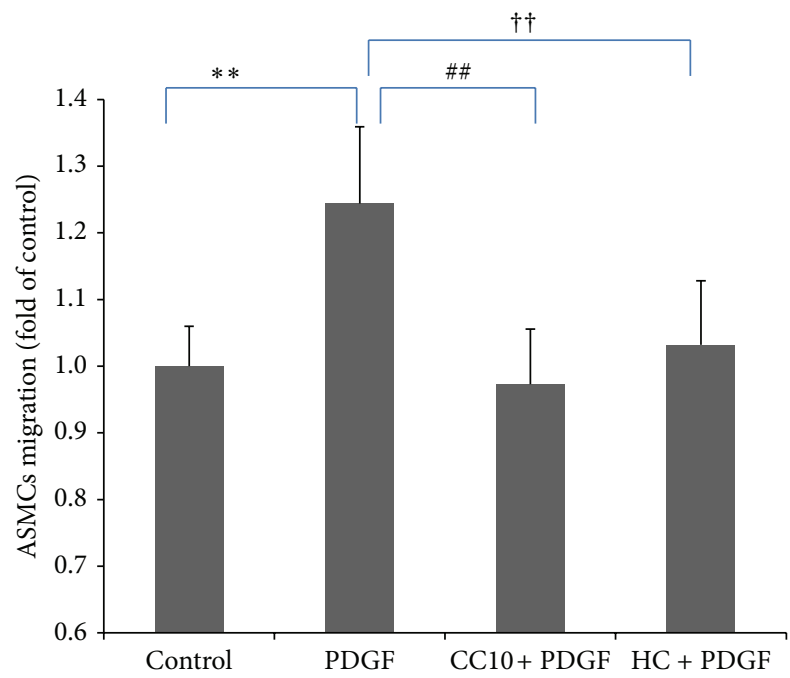

FIGURE 5: The effects of recombinant rat CC10 protein on PDGFBB-induced ASMCs migration. The migration assay was performed using the Transwell system. Migrated cells were determined by counting the cells that migrated to the lower side of the filter using a microscope. Six randomly selected fields were counted, and each sample was assayed in triplicate. Data was shown as means \pm SD values. ${ }^{* *} P<0.01$ PDGF group versus control, ${ }^{\# \#} P<0.01$ CC10 group versus PDGF group, and ${ }^{\dagger \dagger} P<0.01 \mathrm{HC}$ group versus PDGF group.
3.3. Recombinant Rat CC10 Protein Suppresses PDGF-BBInduced ASMCs Migration. In the Boyden chamber assay system, stimulation with PDGF-BB $(25 \mathrm{ng} / \mathrm{mL})$ for $8 \mathrm{~h}$ increased ASMCs migration to about $124 \%$ compared with the PBS control $(P<0.01)$. This migration response to PDGF-BB stimulation was significantly suppressed by CC10 $(400 \mathrm{ng} / \mathrm{mL})$ to $78 \%$ compared to the PDGF group $(P<0.01)$. HC $(1 \mathrm{mg} / \mathrm{mL})$ could inhibit this PDGF-induced cell migration to about $83 \%$ compared to the PDGF group $(P<0.01)$. It was worth noting that this inhibitory effect of CC10 protein on PDGF-induced ASMCs migration was stronger than that of HC (Figure 5).

3.4. Recombinant Rat CC10 Protein Suppresses PDGF-BBInduced Cyclin D1 Expression. To further elucidate the inhibitory effect of CC10 protein on ASMCs proliferation and migration, we investigated the effect of $\mathrm{CC} 10$ protein on cell cycle regulatory protein cyclin D1 expression. Cyclin D1 expression was increased significantly in ASMCs after stimulation with PDGF-BB $(25 \mathrm{ng} / \mathrm{mL})$ for $24 \mathrm{~h}$ and $48 \mathrm{~h}$ compared to the PBS control $(P<0.05)$. Pretreatment with $\mathrm{CC10}(400 \mathrm{ng} / \mathrm{mL})$ reduced PDGF-BB-induced expression of cyclin D1 (Figure 6).

\section{Discussion}

CC10 is a steroid-inducible, homodimeric, and low molecular weight secretory protein. It is suggested that natural CC10 


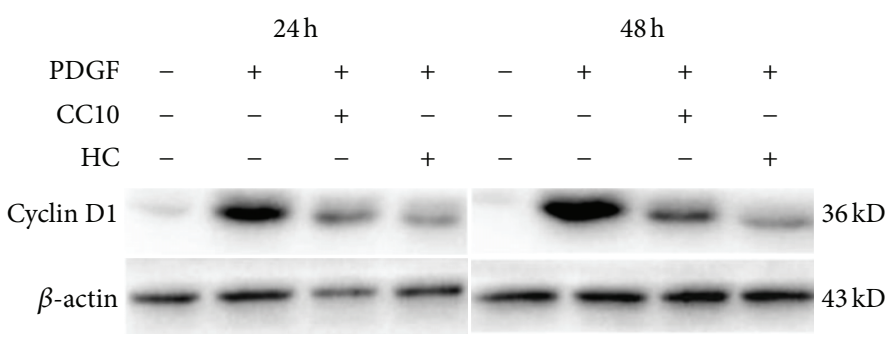

(a)

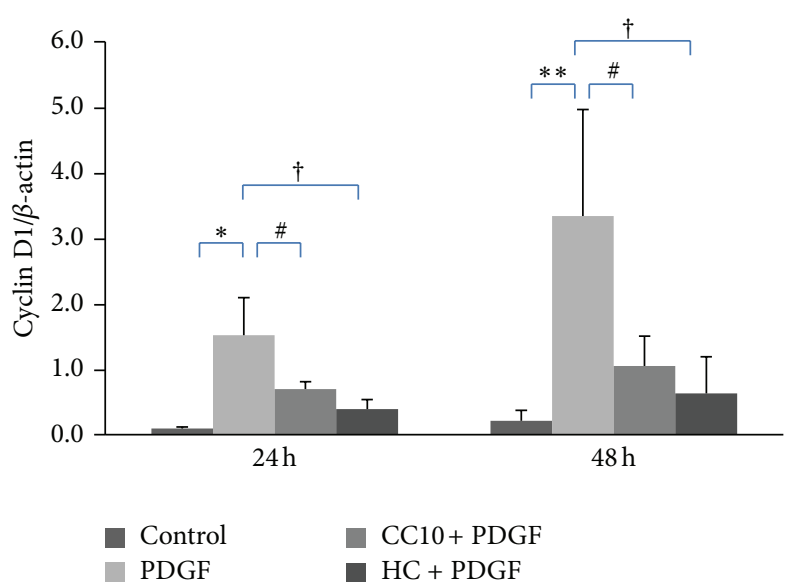

(b)

FIGURE 6: The effects of recombinant rat CC10 protein on PDGF-BB-induced cyclin D1 expression. (a) Western blot analysis of cyclin D1 expression. (b) The expression of cyclin D1 was quantified and represented as band intensity normalized to $\beta$-actin. Data was shown as means \pm SD values. ${ }^{* *} P<0.01$ PDGF group versus control, ${ }^{*} P<0.05$ PDGF group versus control, ${ }^{*} P<0.01$ CC10 group versus PDGF group, and ${ }^{\dagger} P<0.05 \mathrm{HC}$ group versus PDGF group.

is difficult to obtain in amounts sufficient for the detailed characterization of its biological properties. It has been recognized that homodimer proteins with two interchain disulfide bonds are very difficult to express in their natural quaternary structure in bacterial hosts [26]. The pET system is the most powerful system developed for the cloning and expression of recombinant proteins in E. coli. In our experimental system, CC10 DNA was cloned in pET-22b plasmid and transferred into BL21 (DE3). Recombinant rat CC10 protein expression was induced by IPTG. Our results demonstrated that after IPTG induction, recombinant CC10 had been stably expressed in the pET-22b recombinant plasmid. However, in our early experiments, more than half of this protein was expressed in the insoluble pellet. Lower growth temperatures have been shown to prevent aggregation into insoluble inclusion bodies [27]. To improve the yield of active soluble recombinant CC10 protein, we performed temperature and time course experiments which aimed to optimize the induction temperature and time as well as the IPTG concentration. After a series of trials, we arrived at the optimal conditions induction of the recombinant vector with $0.4 \mathrm{mM}$ IPTG for $4 \mathrm{~h}$ at $21^{\circ} \mathrm{C}$. For recombinant rat CC10 protein purification, we used affinity chromatography and ion-exchange chromatography purification in order to obtain high purity recombinant protein. We chose $\mathrm{Ni}^{2+}$ Sepharose 6 Fast Flow and Q Sepharose Fast Flow beads according to the characteristics of the pET-22b plasmid and the CC10 protein as well as the elution buffer used in affinity chromatography purification. After the two-step purification, we obtained recombinant rat CC10 protein with high purity.

ASM proliferation and migration is a major pathological component in airway remodeling of asthma. In vitro studies demonstrated that ASMCS from asthmatics exhibited increased proliferation capacity compared to myocytes from nonasthmatic individuals $[28,29]$. ASMCs in asthmatic airways remodeled inward towards the mucosal layer, and this pathological change was thought to result from ASMCs migration in response to growth and chemokinetic factors [30]. PDGF-BB was one of those factors responsible for the ASMCs proliferation and migration in airway remodeling [31]. In our experiments, we chose PDGF-BB as an inducer to induce ASMCs proliferation and migration. Stimulation with PDGF-BB significantly promoted ASMCs proliferation both in the WST-1 system and the Roche RTCA DP assay system. Previous studies demonstrated that ASMCs could be changed from a quiescent to a migratory and proliferative phenotype by exposure to a variety of growth factors and cytokines in asthma [32-34]. In our Boyden chamber assay system, stimulation with PDGF-BB significantly improved the ASMCs migration. Our results demonstrated that PDGF-BB significantly induced ASMCs proliferation and migration, which was one of the key pathological changes of airway remodeling in asthma, and our discovery was the same as results of former studies [30, 31]. Frequent stimulation of ASMCS by growth factors, contractile agonists, and inflammatory mediators could cause airway remodeling and airflow obstruction, some of which can become irreversible [34]. Decreasing cell proliferation and reducing cell migration into the smooth muscle layer are two mechanisms which could limit the accumulation of smooth muscle in airway remodeling [35]. In our study, we observed the effect of the CC10 protein on ASMCs proliferation and migration. Stimulation with PDGF$\mathrm{BB}$ significantly promoted ASMCs proliferation and migration, and CC10 protein significantly inhibited this proliferation and migration, indicating that CC10 might be used to prevent ASMCs proliferation and migration in airway remodeling in asthma. The cell cycle regulatory protein cyclin D1 has been the most widely studied cyclin in ASM biology [34]. Our study showed here that cyclin D1 expression was activated in ASMCs by PDGF-BB stimulation, which was in accordance with other studies [36, 37]. The activation of cyclin D1 is necessary for transition through the restriction 
point into DNA synthesis [38] and is associated with ASMCs proliferation [37, 39]. In the present study, PDGF-BB induced a high level of cyclin D1 activation, and CC10 protein inhibited PDGF-BB-induced cyclin D1 expression significantly in ASMCs. These results revealed that the antiproliferative and antimigrative effect of CC10 protein might be associated with downregulation of cyclin D1 expression.

$\mathrm{HC}$ is one of the commonly used glucocorticoids in asthma treatment, and long term usage of it might bring some side effects, especially, for children with asthma. CC10 is a naturally secreted protein in our body with almost the same inhibitory effect as that of HC on PDGF-BB-induced ASMCs proliferation and migration, and to some extent, it might be developed into a substitute for HC in inhibiting disorders regarding abnormal ASMCs proliferation and migration.

In our experiment, we investigated the effect of recombinant rat CC10 protein on PDGF-BB-induced ASMCs proliferation and migration. Our results showed that $\mathrm{CC} 10$ protein could inhibit ASMCs proliferation and migration, which were responsible for airway wall thickness in airway remodeling. The suppression of ASMCs proliferation and migration might be associated with downregulation of cyclin D1 expression. Our discovery might offer hope for the future treatment of airway remodeling.

\section{Acknowledgments}

This work was supported by the National Natural Science Foundation of China (81173332, 81173341, 81202753, and 81001548). The authors thank Professor Qing-Hua Zhang and Doctor Kai Song for providing technical guidance for recombinant plasmid construction and thank Doctor ZhiYuan Zhu for providing technical guidance for recombinant protein purification.

\section{References}

[1] E. Tagaya and J. Tamaoki, "Mechanisms of airway remodeling in asthma," Allergology International, vol. 56, no. 4, pp. 331-340, 2007.

[2] Y. Sumi and Q. Hamid, "Airway remodeling in asthma," Allergology International, vol. 56, no. 4, pp. 341-348, 2007.

[3] N. Carroll, J. Elliot, A. Morton, and A. James, "The structure of large and small airways in nonfatal and fatal asthma," American Review of Respiratory Disease, vol. 147, no. 2, pp. 405-410, 1993.

[4] J. K. Bentley and M. B. Hershenson, "Airway smooth muscle growth in asthma: proliferation, hypertrophy, and migration," Proceedings of the American Thoracic Society, vol. 5, no. 1, pp. 89-96, 2008.

[5] R. Halwani, S. Al-Muhsen, and Q. Hamid, "Airway remodeling in asthma," Current Opinion in Pharmacology, vol. 10, no. 3, pp. 236-245, 2010.

[6] D. M. Murphy and P. M. O'Byrne, "Recent advances in the pathophysiology of asthma," Chest, vol. 137, no. 6, pp. 1417-1426, 2010.

[7] L. Fredriksson, H. Li, and U. Eriksson, “The PDGF family: four gene products form five dimeric isoforms," Cytokine and Growth Factor Reviews, vol. 15, no. 4, pp. 197-204, 2004.
[8] S. Feske, Y. Gwack, M. Prakriya et al., "A mutation in Orail causes immune deficiency by abrogating CRAC channel function," Nature, vol. 441, no. 7090, pp. 179-185, 2006.

[9] I. Ohno, Y. Nitta, K. Yamauchi et al., "Eosinophils as a potential source of platelet-derived growth factor B-chain (PDGF-B) in nasal polyposis and bronchial asthma," American Journal of Respiratory Cell and Molecular Biology, vol. 13, no. 6, pp. 639647, 1995.

[10] S. Shimizu, E. C. Gabazza, T. Hayashi, M. Ido, Y. Adachi, and K. Suzuki, "Thrombin stimulates the expression of PDGF in lung epithelial cells," American Journal of Physiology-Lung Cellular and Molecular Physiology, vol. 279, no. 3, pp. L503-L510, 2000.

[11] I. Ito, E. D. Fixman, K. Asai et al., "Platelet-derived growth factor and transforming growth factor- $\beta$ modulate the expression of matrix metalloproteinases and migratory function of human airway smooth muscle cells," Clinical and Experimental Allergy, vol. 39, no. 9, pp. 1370-1380, 2009.

[12] J. A. Elias, "Airway remodeling in asthma: unanswered questions," American Journal of Respiratory and Critical Care Medicine, vol. 161, no. 3, pp. S168-S171, 2000.

[13] G. Singh and S. L. Katyal, "Clara cells and Clara cell 10 $\mathrm{kD}$ protein (CC10)," American Journal of Respiratory Cell and Molecular Biology, vol. 17, no. 2, pp. 141-143, 1997.

[14] G. Singh, S. L. Katyal, and S. A. Gottron, "Antigenic, molecular and functional heterogeneity of Clara cell secretory proteins in the rat," Biochimica et Biophysica Acta, vol. 829, no. 2, pp. 156163, 1985.

[15] A. B. Mukherjee, G. C. Kundu, G. Mantile-Selvaggi et al., "Uteroglobin: a novel cytokine?" Cellular and Molecular Life Sciences, vol. 55, no. 5, pp. 771-787, 1999.

[16] T. C. Umland, S. Swaminathan, G. Singh et al., "Structure of a human Clara cell phospholipid-binding protein-ligand complex at 1.9 Å resolution,” Nature Structural Biology, vol. 1, no. 8, pp. 538-545, 1994.

[17] X. B. Long, S. Hu, N. Wang, H. T. Zhen, Y. H. Cui, and Z. Liu, "Clara cell 10-kDa protein gene transfection inhibits NF-kappaB activity in airway epithelial cells," PLoS One, vol. 7, Article ID e35960, 2012.

[18] P. Katavolos, C. A. Ackerley, M. E. Clark, and D. Bienzle, "Clara cell secretory protein increases phagocytic and decreases oxidative activity of neutrophils," Veterinary Immunology and Immunopathology, vol. 139, no. 1, pp. 1-9, 2011.

[19] X. M. Gioldassi, H. Papadimitriou, V. Mikraki, and N. K. Karamanos, "Clara cell secretory protein: determination of serum levels by an enzyme immunoassay and its importance as an indicator of bronchial asthma in children," Journal of Pharmaceutical and Biomedical Analysis, vol. 34, no. 4, pp. 823-826, 2004.

[20] R. Ray, Z. Zhang, Y.-C. Lee, J.-L. Gao, and A. B. Mukherjee, "Uteroglobin suppresses allergen-induced TH2 differentiation by down-regulating the expression of serum amyloid $\mathrm{A}$ and SOCS-3 genes," FEBS Letters, vol. 580, no. 25, pp. 6022-6026, 2006.

[21] A. K. Mandal, R. Ray, Z. Zhang, B. Chowdhury, N. Pattabiraman, and A. B. Mukherjee, "Uteroglobin inhibits prostaglandin F2 $\alpha$ receptor-mediated expression of genes critical for the production of pro-inflammatory lipid mediators," Journal of Biological Chemistry, vol. 280, no. 38, pp. 32897-32904, 2005. 
[22] N. Ke, X. Wang, X. Xu, and Y. A. Abassi, "The xCELLigence system for real-time and label-free monitoring of cell viability," Methods in Molecular Biology, vol. 740, pp. 33-43, 2011.

[23] J. M. Atienza, N. Yu, S. L. Kirstein et al., "Dynamic and labelfreee cell-based assays using the real-time cell electronic sensing system," Assay and Drug Development Technologies, vol. 4, no. 5, pp. 597-607, 2006.

[24] R. Limame, A. Wouters, B. Pauwels et al., "Comparative analysis of dynamic cell viability, migration and invasion assessments by novel real-time technology and classic endpoint assays," PloS One, vol. 7, no. 10, Article ID e46536, 2012.

[25] Y.-D. Xu, J.-M. Cui, Y. Wang et al., “The early asthmatic response is associated with glycolysis, calcium binding and mitochondria activity as revealed by proteomic analysis in rats," Respiratory Research, vol. 11, article 107, 2010.

[26] G. Mantile, L. Miele, E. Cordella-Miele, G. Singh, S. L. Katyal, and A. B. Mukherjee, "Human Clara cell 10-kDa protein is the counterpart of rabbit uteroglobin," Journal of Biological Chemistry, vol. 268, no. 27, pp. 20343-20351, 1993.

[27] H. P. Sørensen and K. K. Mortensen, "Soluble expression of recombinant proteins in the cytoplasm of Escherichia coli," Microbial Cell Factories, vol. 4, article 1, 2005.

[28] P. R. A. Johnson, M. Roth, M. Tamm et al., "Airway smooth muscle cell proliferation is increased in asthma," American Journal of Respiratory and Critical Care Medicine, vol. 164, no. 3, pp. 474477, 2001.

[29] J. K. Burgess, H. L. Jin, Q. I. Ge et al., "Dual ERK and phosphatidylinositol 3-kinase pathways control airway smooth muscle proliferation: differences in asthma," Journal of Cellular Physiology, vol. 216, no. 3, pp. 673-679, 2008.

[30] C. Pepe, S. Foley, J. Shannon et al., "Differences in airway remodeling between subjects with severe and moderate asthma," Journal of Allergy and Clinical Immunology, vol. 116, no. 3, pp. 544-549, 2005.

[31] J. A. Hirota, K. Ask, L. Farkas et al., "In vivo role of plateletderived growth factor-BB in airway smooth muscle proliferation in mouse lung," American Journal of Respiratory Cell and Molecular Biology, vol. 45, no. 3, pp. 566-572, 2011.

[32] S. J. Hirst, J. G. Martin, J. V. Bonacci et al., "Proliferative aspects of airway smooth muscle," Journal of Allergy and Clinical Immunology, vol. 114, no. 2, pp. S2-S17, 2004.

[33] J. F. Perez-Zoghbi, C. Karner, S. Ito, M. Shepherd, Y. Alrashdan, and M. J. Sanderson, "Ion channel regulation of intracellular calcium and airway smooth muscle function," Pulmonary Pharmacology and Therapeutics, vol. 22, no. 5, pp. 388-397, 2009.

[34] A. L. Lazaar and R. A. Panettieri Jr., "Airway smooth muscle: a modulator of airway remodeling in asthma," Journal of Allergy and Clinical Immunology, vol. 116, no. 3, pp. 488-495, 2005.

[35] B. Camoretti-Mercado, "Targeting the airway smooth muscle for asthma treatment," Translational Research, vol. 154, no. 4, pp. 165-174, 2009.

[36] F. Das, L. Mahimainathan, N. Ghosh-Choudhury et al., “TGF $\beta$ intercepts nuclear glycogen synthase kinase $3 \beta$ to inhibit PDGF-induced DNA synthesis in mesangial cells," FEBS Letters, vol. 581, no. 27, pp. 5259-5267, 2007.

[37] J. C. Allen, P. Seidel, T. Schlosser, E. E. Ramsay, Q. Ge, and A. J. Ammit, "Cyclin D1 in ASM cells from asthmatics is insensitive to corticosteroid inhibition," Journal of Allergy, vol. 2012, Article ID 307838, 6 pages, 2012.
[38] C. J. Sherr and J. M. Roberts, "CDK inhibitors: positive and negative regulators of G1-phase progression," Genes and Development, vol. 13, no. 12, pp. 1501-1512, 1999.

[39] C.-L. Du, Y.-J. Xu, X.-S. Liu et al., "Up-regulation of cyclin D1 expression in asthma serum-sensitized human airway smooth muscle promotes proliferation via protein kinase $\mathrm{C} \alpha$," Experimental Lung Research, vol. 36, no. 4, pp. 201-210, 2010. 

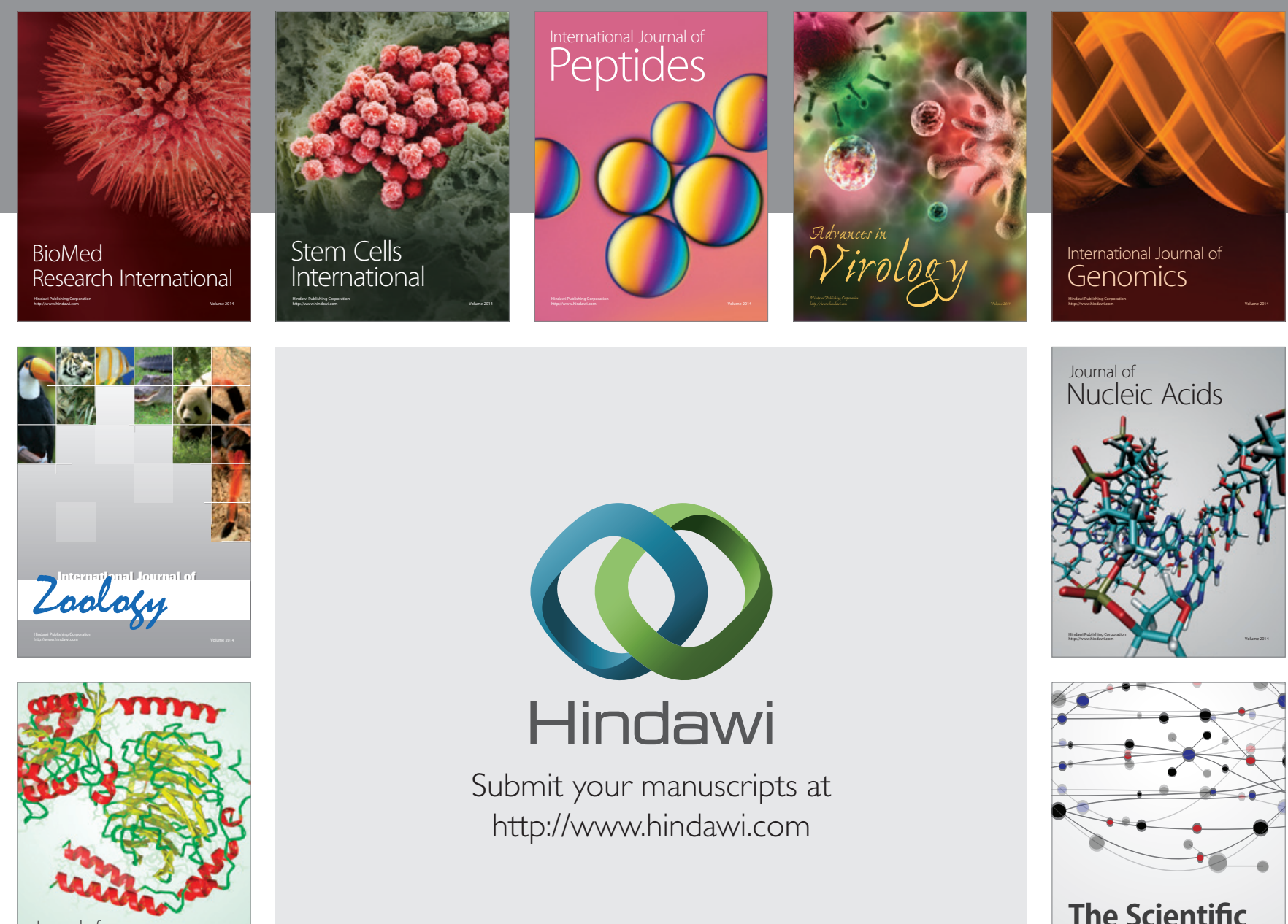

Submit your manuscripts at

http://www.hindawi.com

Journal of
Signal Transduction
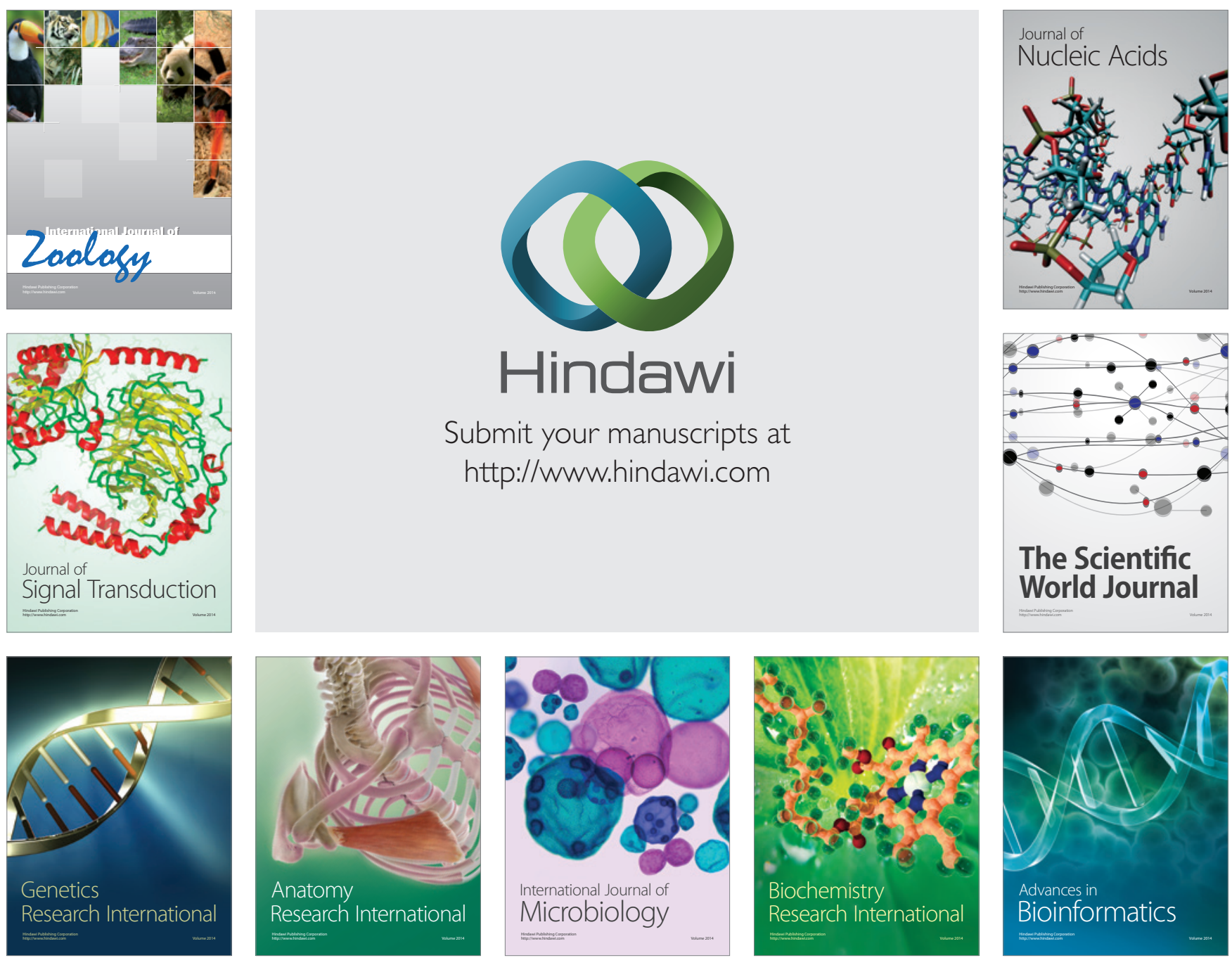

The Scientific World Journal
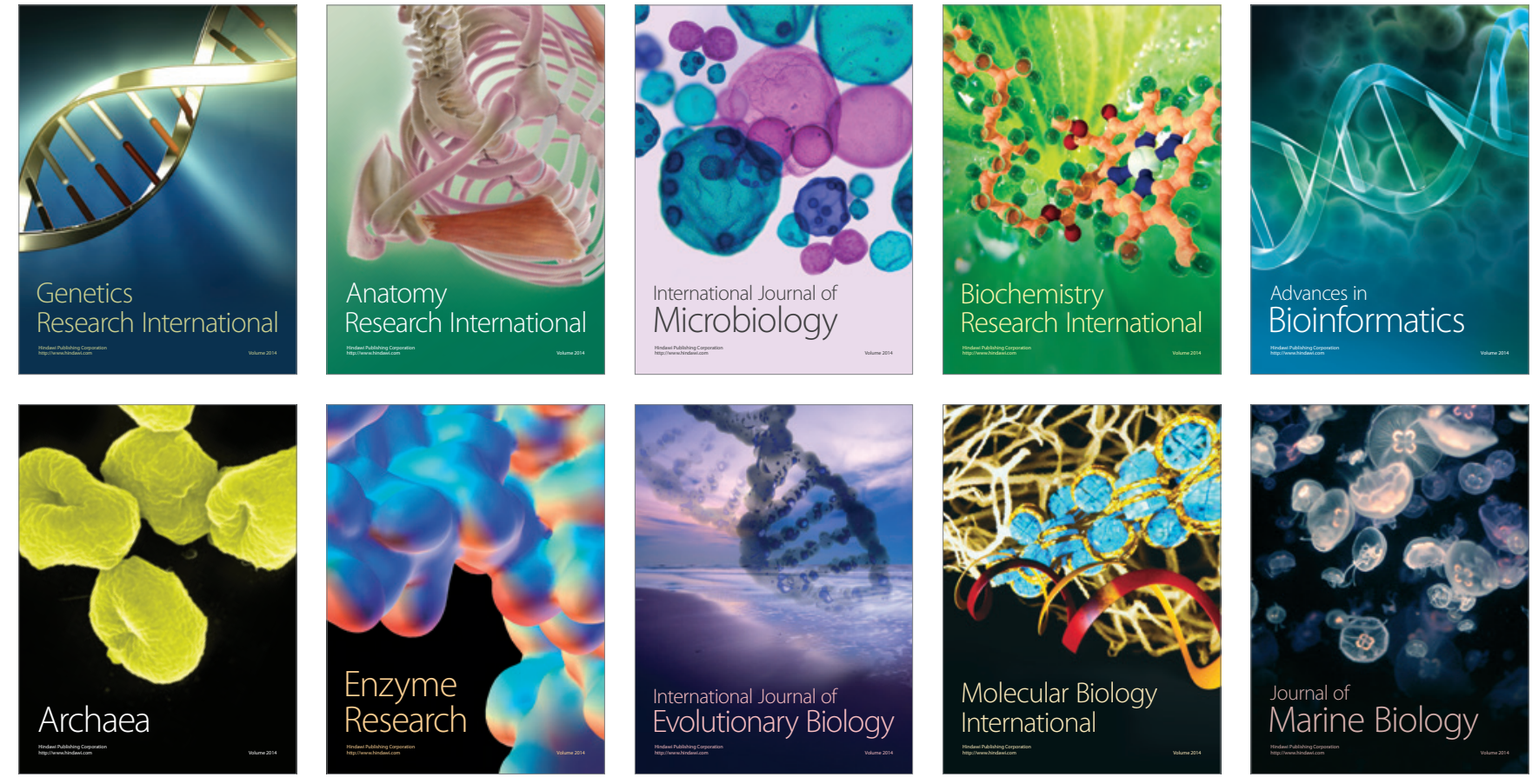